\title{
Intertextualidad audiovisual en prácticas estético-políticas online. El caso del Colectivo Los Ingrávidos
}

\author{
JOSÉ ALBERTO ABRIL VALDEZ
}

El objetivo de este artículo es analizar las prácticas creativas conectadas a la red -online- en las que la imagen digital adquiere un papel central en procesos en los que se propone repensar y cuestionar, desde lo estético, el lenguaje audiovisual y la industria mediática, así como la realidad político-social de México. Se toma como caso de estudio al Colectivo Los Ingrávidos - grupo de videastas mexicanos que adopta plataformas y redes sociales como su campo de acción-, y desde la perspectiva de la cultura digital, por medio del análisis intertextual, se reflexiona en torno a su producción. Se concluye que estas prácticas, como parte de procesos ciberactivistas, tienden a estetizar las preocupaciones sociopolíticas de un determinado momento, al vincular sus constantes a las del "artivismo" y recurrir a ejercicios propios de la posproducción -el remix audiovisual y la intertextualidad-como estrategias de interpelación.

PALABRAS CLAVE: cultura transmedia, comunicación audiovisual, intertextualidad, ciberactivismo, remix

\section{Audiovisual Intertextuality in Online Aesthetic-Political Practices. The Case of Colectivo Los Ingrávidos}

The objective of this article is to analyze the online creative practices in which the digital image acquires a central role, in processes where it is proposed to rethink and question, from an aesthetic point of view, both a language-the audiovisual and media industry-and a sociopolitical reality-that of Mexico-. Colectivo Los Ingrávidos-a group of Mexican videographers that adopts platforms and social networks as their field of action-is taken as a case of study, and from the perspective of the digital culture, through intertextual analysis, we reflect on its production. It is concluded that these practices, as part of cyberactivist processes, tend to aestheticize the sociopolitical concerns of a certain moment, linking their constants with those of "artivism" by resor-

José ALBERTO AbriL VALDEZ

Universidad de Sonora,

Hermosillo, Sonora, México seis14@yahoo.com.mx ting to post-production exercises-the audiovisual remix and intertextualityas interpellation strategies.

KEYWORDS: transmedia culture, audiovisual communication, intertextuality, cyber-activism, remix 
Introducción: imagen y cultura digital

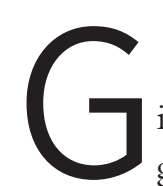

illes Lipovetsky y Jean Serroy (2009) afirman que en menos de medio siglo hemos pasado de la pantalla-espectáculo a la pantalla-comunicación, de la unipantalla a la omnipantalla, y que bajo esa misma lógica evolutiva el presente puede describirse como el siglo de la "pantalla global". Se refieren al carácter omnipresente de la imagen y la centralidad que ésta ha adquirido en menos de 20 años, como consecuencia lógica de las tecnologías de la información y la comunicación, que han traído consigo la ampliación de nuestra iconosfera.

En particular, internet es el fenómeno que ha contribuido a esta transformación del ecosistema audiovisual (Abril y León, 2017). Internet y los procesos de digitalización no sólo han permitido la fácil circulación de imágenes de toda naturaleza, también han introducido cambios en las formas de creación audiovisual, así como en nuestras maneras de aproximarnos a ellas en tanto usuarios; y el papel del usuario, sus prácticas de consumo y producción, es el que ha estado provocando lo que Roberto Igarza (2010: 86) llama "la audiovisualización de la web", haciendo eco de Lipovetsky y Serroy (2009).

En ese sentido, prácticamente es imposible hablar de la imagen sin vincularla a la cultura digital y a ese conjunto de prácticas dotadas de sentido, y a la vez, cargar de significación al ciberespacio, así como a todos los dispositivos que nos conducen a él. De acuerdo con Elisenda Ardèvol et al. (2010), la cultura digital nos remite a un conjunto de procesos emergentes que se generan a partir de interacciones complejas entre las tecnologías digitales y las infraestructuras en red; es decir, un conjunto amplio y variado de prácticas, dispositivos materiales y narrativas relacionadas con la producción cultural contemporánea, que tiene su origen en los usos de las tecnologías digitales de la comunicación y la información.

En esta serie de procesos emergentes, los contenidos audiovisuales han cobrado un papel fundamental porque lo digital — tecnológica y simbólicamente hablando- le ha dado un carácter ubicuo a la imagen (Brea, 2007; Bourriaud, 
2014). Por lo mismo, es difícil pensar, definir y conceptualizar los procesos culturales globales sin el ingrediente que lo visual o audiovisual proporciona, pues como bien nos recuerda Arjun Appadurai (2001), la imagen y la imaginación son ahora centrales en todas las formas de agencia, un hecho social en sí mismo y el componente fundamental del nuevo orden global.

Una de esas formas de agencia, vinculada de manera estrecha a la cultura digital, en la que se reconoce en particular el enorme valor de la imagen y la imaginación como un hecho social a la vez que estético y político, es precisamente el ciberactivismo.

En el presente artículo se propone una reflexión sobre la naturaleza política de ciertas prácticas creativas en las que la imagen digital adquiere un papel fundamental, en procesos en los cuales se aspira a repensar y cuestionar desde lo estético tanto un lenguaje - lo audiovisual y su papel en la industria mediática - como una realidad política y social — la de México-. En primera instancia, formulamos una descripción del activismo en ámbitos virtuales y la importancia que en él cobra el lenguaje audiovisual. Se toma como caso de estudio el Colectivo Los Ingrávidos, grupo de videastas mexicanos que adopta plataformas virtuales, así como redes sociales, como su campo de acción.

Después, centramos nuestro análisis en la producción de dicho colectivo. Desde la perspectiva de la cultura transmedia, y en un análisis intertextual, se reflexiona en torno a la producción, conformada en su mayoría por ejercicios de apropiación audiovisual con un fuerte acento experimental. Con el propósito de profundizar al respecto, nos concentramos en dos ejercicios de apropiación y remix para puntualizar cómo opera la intertextualidad. Previamente, definiremos a qué nos referimos cuando hablamos de intertextualidad, y en especial, en qué consiste un análisis intertextual.

Finalmente, se concluye que el ciberactivismo, en el ámbito virtual, tiende a estetizar las preocupaciones sociopolíticas de un determinado

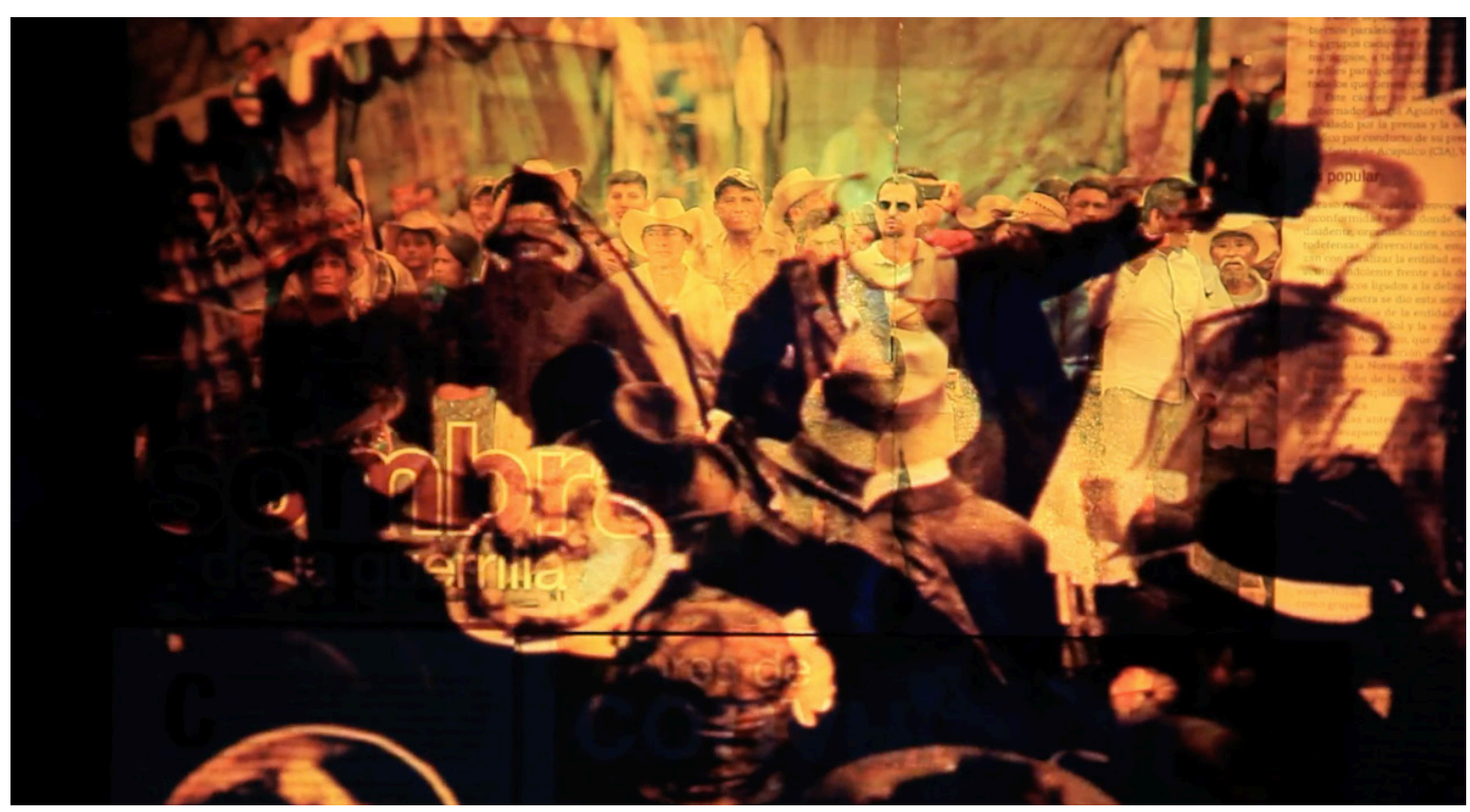

Colectivo Los Ingrávidos • Gabinete de seguridad (2016). 
momento, al relacionar sus constantes con las del "artivismo" mientras recurre a los ejercicios formales, los procedimientos propios de la llamada posproducción, la apropiación reflexiva de la cultura cinematográfica, el remix audiovisual y la intertextualidad como estrategias de interpelación.

\section{Ciberactivismo: imagen digital, prácticas creativas y ciudadanía}

De acuerdo con Carlos Scolari (2014), el poder funciona cada vez más en redes globales y la gente tiene sus vivencias, construye sus valores, sus trincheras de resistencia y de alternativas en sociedades locales:

\begin{abstract}
El gran problema que se plantea es cómo, desde lo local, se puede controlar lo global, cómo desde mi vivencia y mi relación con mi mundo local [...] puedo oponerme a la globalización, a la destrucción del medio ambiente, a la masacre del tercer mundo... ¿Cómo se puede hacer esto? Pues bien, Internet permite la articulación de proyectos alternativos locales mediante protestas globales que acaban aterrizando en algún lugar... pero que se constituyen, se organizan y se desarrollan a partir de la conexión Internet (2014: 11).
\end{abstract}

Por otra parte, Tommaso Gravante y Alice Poma (2013) plantean que es difícil imaginar la movilidad social y política sin pensar en los medios de comunicación alternativos e independientes. Mucho más en estos años que corren, las tecnologías de la comunicación y la información, internet y los nuevos dispositivos tecnológicos también han introducido cambios en los modos de participación y en la percepción misma de la participación, así como en las formas de resistencia y las maneras de manifestar el sentimiento de inconformidad respecto a un estado de cosas. Los medios alternativos e independientes se vuelven tales en la red, y gracias a ellos y a la red, la inconformidad local, nacional, global, gana centralidad y visibilidad (Scolari, 2014).

El ciberactivismo se refiere precisamente a todo lo anterior. En términos muy concretos, se le suele definir como un conjunto de acciones coordinadas de colectivos movilizados mediante la comunicación en red interactiva, distribuida en buena medida gracias a la propagación viral que las diferentes plataformas y redes sociales facilita y que les da cierta trascendencia transnacional (Scolari, 2014).

Habría que agregar que si bien internet ha facilitado la articulación de proyectos contestatarios, la imagen — lo audiovisual — ha resultado un recurso privilegiado en la expansión de esos proyectos, en su capacidad de propagación (Jenkins, Ford y Green, 2015). Al respecto, podemos recordar, por ejemplo, desde las apropiaciones lúdicas, creativas e incisivas de contenidos mediáticos e informativos por parte de usuarios ingeniosos que generan una acelerada y cotidiana producción de memes, hasta proyectos más ambiciosos por su dimensión transmedia y global, como Everyday Rebellion, ${ }^{1}$ en el que se convoca a los ciudadanos a que mediante cámaras de teléfonos inteligentes hagan un registro audiovisual de toda aquella movilización política y social que se desarrolle en cualquier parte del mundo para posteriormente integrarlo a una red global de movilizaciones mediatizadas.

Recordemos también el movimiento mexicano \#YoSoy132, que tuvo como piedra angular la difusión en redes sociales de un video en el que el candidato a la Presidencia Enrique Peña Nieto se dirigió a los estudiantes en las instalaciones de la Universidad Iberoamericana, en la Ciudad de México, en 2012, lo cual dio origen a una evolución transmedia espontánea, simultánea al desarrollo del movimiento, que encontró diversas plataformas para su diseminación audiovisual online.

1 Véase <http://www.everydayrebellion.net/>. 
En todas esas prácticas, lo audiovisual se nos ha presentado como formato transversal. Si internet es la conexión global/local y la nueva forma de control y movilización social en nuestra sociedad (Scolari, 2014), los usuarios, con sus prácticas, se han encargado de visibilizar esas movilizaciones. Parafraseando a Igarza (2010), podemos afirmar que los usuarios están "audiovisualizando" la web, y con ello, sus prácticas ciudadanas.

\section{Entre el ciberactivismo y el "artivismo": el caso del Colectivo Los Ingrávidos}

Entre esos variados ejemplos de prácticas activistas que privilegian el uso de la imagen se encuentra nuestro caso de estudio: el Colectivo Los Ingrávidos. ${ }^{2}$ Este colectivo de origen mexicano está formado por personas dedicadas a trabajar con lo audiovisual — diseñadores y videastas — desde una posición puramente creativa, a la vez que política, en la que la imagen no sólo es un medio con el cual experimentar para buscar otras formas de representación audiovisual mediante la manipulación digital, sino también de cuestionar, con ello, una estética dominante y una realidad sociopolítica (Cuevas, 2016).

Su interés por la imagen los ubica a medio camino entre el ciberactivismo y el "artivismo" en línea (Incarbone y Wiedemann, 2016). En ese sentido, sus objetivos están encaminados, por un lado, a establecer una sintonía con las preocupaciones de la ciudadanía mexicana actual, manifestas en las redes sociales, y contribuir al debate público mediante el uso del hashtag - \#TodosSomosAyotzinapa, \#MoverMéxico, \#NiUnaMás, \#DíaInternacionaldelaMujer, etc.—, y por el otro, a mantener una postura crítica respecto a los contenidos audiovisuales que los medios de comunicación tradicionales - Televisa y TV Aztecadifunden, al reivindicar, recuperar y transformar de manera reflexiva la cultura televisiva y cinematográfica consumida tradicionalmente por la audiencia mexicana (Cuevas, 2016). Los ingrávidos realizan sus prácticas creativas apelando a aquella idea propuesta por el cineasta experimental Jonas Mekas — figura paradigmática del "artivismo" de los años sesentade que el arte debe ser un acto político, siempre rebelde y en oposición (Gubern, 2014).

Por sus formas de proceder, el ciberactivismo del Colectivo Los Ingrávidos es de naturaleza transmedia. Cuando hablamos de transmedia o transmediación, nos referimos a ambientes en los que se diluyen las barreras divisorias de los soportes y los formatos de contenidos, para constituir nuevas realidades mediáticas que sólo tienen sentido en un entorno digital. Las prácticas de consumo y producción adquieren así un carácter expansivo porque los contenidos se dispersan por distintas plataformas a medida que los recursos tecnológicos se diversifican y amplían (Scolari, 2013; Jenkins, Ford y Green, 2015).

Para conceptualizar este tipo de acciones y otras más, propias de los ambientes transmedia, Henry Jenkins, Sam Ford y Joshua Green (2015) introducen el concepto de "propagabilidad". La capacidad de propagación se refiere, en específico, al potencial tanto técnico como cultural del público a la hora de compartir contenido con sus propósitos particulares. Así, la capacidad de propagación propia de los procesos transmedia es consecuencia de cambios en la naturaleza de las tecnologías que hacen que sea más fácil producir, subir, bajar, incautar, reversionar, recircular e insertar contenido: "la digitalización hace que cambiar formatos sea más simple y distribuir contenidos más barato” (Jenkins, Ford y Green, 2015: 319).

Bajo esa lógica se propone el análisis del trabajo del Colectivo Los Ingrávidos, pues su campo de acción es enteramente el ciberespacio. En ese sentido, el nombre con el que se autodenominan tiene 
relación con ello: lo ingrávido como una entidad colectiva paradójicamente flotante y fluctuante, de acuerdo con los acontecimientos offline; una entidad ubicua a la vez que inaprehensible. Sus acciones creativas se dispersan por varias plataformas online, como la propia comunidad de Facebook, su sitio web o su canal en Vimeo, además de ayudarse a diseminar sus trabajos, mediante el uso del hashtag, como ya lo señalamos.

Destruir, demoler, someter, convertir las formas de lenguaje audiovisual establecidas, impuestas e institucionalizadas es su consigna. La manipulación de lo audiovisual mediante lo digital también forma parte de sus tácticas. Como veremos más adelante, éstas consisten en ejercicios de apropiación de contenidos mediáticos relacionados con cuestiones del acontecer político y social de nuestro país, mediante la digitalización y las nuevas tecnologías. Lo digital le sirve al Colectivo para desmontar las verdades que los medios oficiales difunden, a partir de una serie de ejercicios creativos.

\section{La intertextualidad: estética, poética y política del remix}

¿Cómo procede el Colectivo Los Ingrávidos en sus ejercicios y prácticas creativas? De acuerdo con Angélica Cuevas Portilla (2016: 65), el Colectivo Los Ingrávidos trabaja con la representación de la violencia, concretamente la violencia en México. Destituye el sentido de los discursos al intervenir en la gramática del lenguaje audiovisual y emplear diferentes metáforas y figuras retóricas. En ese sentido, como ya lo señalamos, su objetivo no sólo es cuestionar la realidad política de nuestro país sino también las convenciones del lenguaje audiovisual institucionalizado por los medios masivos de comunicación —en este caso, representados por Televisa- Para ello, efectúan procesos de apropiación cinematográfica y televisiva.
Algunos de sus ejercicios son remixes en formato breve, en los que se interseccionan ciertos fragmentos cinematográficos con contenidos televisivos (Bourriaud, 2014; Scolari, 2013). Recordemos que al remix se le reconoce como una práctica muy característica de la cultura digital; su traducción al español es "remezcla" y designa a un conjunto de creaciones de una marcada intertextualidad en el que se procede a la combinación de contenidos de diferentes lenguajes — texto, sonido e imagen-, preexistentes y nuevos, que originalmente no tienen relación entre sí, para crear un nuevo producto. Bajo esta lógica, los usuarios y realizadores toman contenidos, los transforman, agregan otros, los resignifican, los mezclan y los pasan - o no- a otros, que los transforman y vuelven a resignificar (Bourriaud, 2014).

El Colectivo Los Ingrávidos propone remezclas producto de la apropiación de fragmentos de películas clásicas — escenas, planos repetidos- pero subvertidos o resignificados por la alteración del sonido, que remite de manera directa a discursos políticos o declaraciones de funcionarios públicos y situaciones que han provocado malestar social. El mismo procedimiento se lleva a cabo con fragmentos de notas informativas televisadas y trastocadas por el montaje.

Si afirmamos que el trabajo del Colectivo Los Ingrávidos es producto de las tácticas propias del remix, que se significan mediante la intertextualidad, ¿cómo procede un análisis de esta naturaleza? De acuerdo con Lauro Zavala (2007), el análisis intertextual se inscribe dentro del conjunto que comprende el análisis textual. Es decir, es el ejercicio de analizar textos y discursos que desde el punto de vista de la semiótica pueden ser escritos, visuales y audiovisuales, y que interesan para comprender de manera íntegra el objeto. Si hablamos de textos audiovisuales en particular, es un análisis que tiene su raíz en la teoría cinematográfica, en su vertiente semiótica, y en el hecho de que se presupone que todo texto está relacionado con otros textos, de manera 
intencionada o no, como producto de una red de significación.

Para Zavala (1999: 29), no existe una forma definitiva y única de realizar un análisis de este tipo: "puede haber tantas lecturas intertextuales como textos y lectores que establezcan sus propias asociaciones", pero invariablemente todo el procedimiento del análisis tiene como objetivo identificar esas asociaciones textuales, y sobre todo, el sentido que se desprende de ellas y las relaciones con los distintos contextos de significación:

La intertextualidad no es algo que dependa exclusivamente del texto o de su autor; también depende, principalmente, de quien observa el texto y descubre en él una red de relaciones que lo hacen posible como materia significativa en una determinada perspectiva: justamente la perspectiva del observador [...]. En la perspectiva del análisis de la intertextualidad, el texto no es únicamente el vehículo de una significación codificada de antemano, sino parte de una red de asociaciones que el lector produce en el momento de reconocer los textos (1999: 27).

Para aclarar un poco más esta lógica, presentaremos a continuación el análisis intertextual de dos de las producciones de este colectivo. El primero se titula Doblaje y desfase gubernamental y fue publicado en Facebook el 5 de agosto de 2015. ${ }^{3}$ Se trata de un breve remix de tres minutos alusivo al asesinato de Rubén Espinosa, fotoperiodista de la revista Proceso encargado de cubrir las movilizaciones sociales de Veracruz, perpetrado en la Ciudad de México el 1 de agosto de 2015. En las redes sociales, tanto la opinión pública como la sociedad civil responsabilizaban de dichos acontecimientos al entonces gobernador de Veracruz Javier Duarte Ochoa. En los días posteriores al crimen, Duarte Ochoa ofreció un discurso ante los medios de comunicación con el propósito de ofrecer argumentos que trataran de validar su hipotética inocencia. En el discurso, reiteraba la frase "pórtense bien", dirigida a los periodistas que, según él, eran los primeros responsables de esas situaciones por involucrarse con el crimen organizado. No está de más decir que la relación entre Duarte Ochoa y la prensa independiente siempre fue tensa y que el crimen, hasta la fecha, no ha sido resuelto. $^{4}$

Pero volvamos al video. Doblaje y desfase gubernamental toma en préstamo un detalle narrativo de la película $M$, el vampiro de Düsseldorf, película alemana realizada por Fritz Lang en 1931, en la que se cuenta la historia de un asesino responsable de la desaparición y muerte de varios niños en una pequeña provincia de Alemania. En ella, el pueblo mismo es el que atrapa al asesino y decide organizar su propio juicio. El fragmento que se nos presenta en el video corresponde a la escena en la que $\mathrm{M}$, el asesino, en un monólogo público, intenta ofrecer argumentos de su inocencia ante una comunidad incrédula y temerosa.

En este ejercicio, la intertextualidad opera mediante dos planos: el visual y el sonoro. Mientras vemos el desarrollo de la escena, escuchamos el discurso de Duarte Ochoa que sustituye a la voz original del actor - Peter Lorre - en la escena; escuchamos y vemos cómo la voz sincroniza casi a la perfección con el movimiento labial del actor y cómo su cándida gesticulación matiza, de forma irónica, ciertos momentos del discurso de Duarte Ochoa, en especial ese insistente y paternalista "pórtense bien".

El segundo ejercicio, publicado el 20 de enero de 2016, opera más o menos de la misma forma. Se titula Gabinete de seguridad, y tiene una duración de aproximadamente cinco minutos. ${ }^{5}$ Temáticamente,

4 "Pórtense bien" fue una frase que propició la creación de una gran cantidad de memes con el motivo icónico del rostro de Duarte Ochoa, que se propagaron por las redes sociales.

$5 \quad$ Véase Colectivo Los Ingrávidos (2016). 


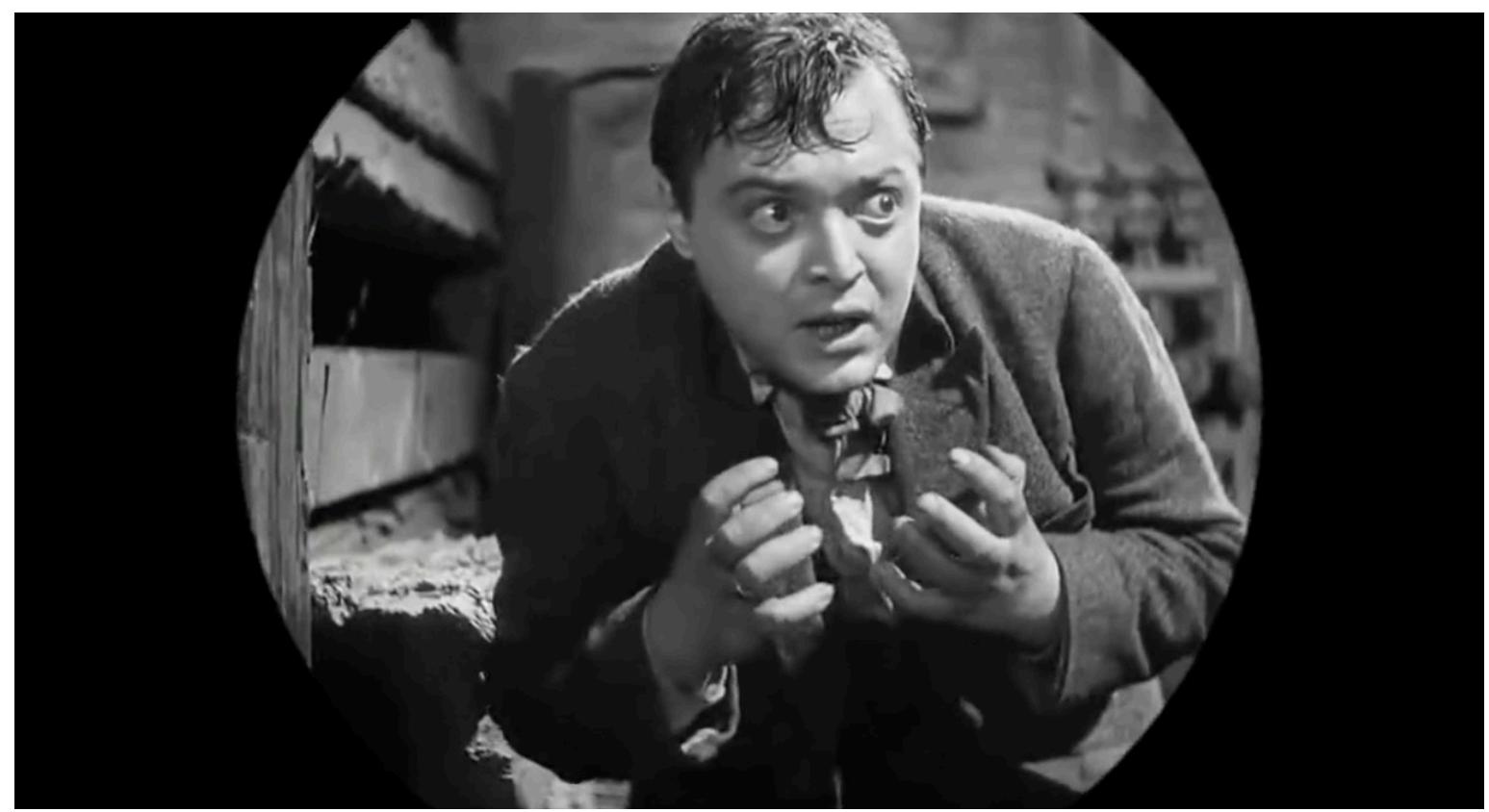

Colectivo Los IngRÁvidos • Doblaje y desfase gubernamental (2015).

se relaciona con la recaptura del narcotraficante Joaquín Guzmán Loera, conocido como el Chapo Guzmán, el 8 de enero de 2016. Momentos después de la captura, Miguel Ángel Osorio Chong, secretario de Gobernación en ese momento, ofreció una notificación pública del acontecimiento ante los medios de comunicación, en el que lo resaltaba como un logro de la administración del presidente Enrique Peña Nieto.

Al igual que en el ejercicio anterior, la intertextualidad se construye a partir de un préstamo —narrativamente hablando- de una película, también de origen alemán, realizada por Robert Wiene en 1920, El gabinete del doctor Caligari. En términos generales, la película original cuenta la historia de un psiquiatra que se dedica a dar espectáculos en ferias populares, en los que presenta a Cesare, un autómata que controla por medio de la hipnosis. Cesare es expuesto como un espectáculo circense durante el día, y por la noche, bajo los efectos de la hipnosis, se dedica a cometer crímenes. En el remix sólo se retoma un fragmento de la película - la escena inicial- en el que vemos al doctor Caligari anunciando su espectáculo ante un nutrido público expectante y la posterior desvelación de Cesare con la apertura de unas cortinas.

Durante cinco minutos vemos el desarrollo de la escena pero la intertextualidad opera en tres planos: el gráfico, el audiovisual y el sonoro. La escena y las imágenes en movimiento, así como la música original de la película, se desarrollan con normalidad, pero ahora las imágenes aparecen proyectadas sobre una fotografía - imagen fija - de una manifestación popular, sobre la que se puede leer la frase: "La sombra de la guerrilla". Durante el desarrollo de este fragmento, escuchamos el discurso en off ${ }^{6}$ de Osorio Chong notificando la captura de Guzmán Loera.

En ambos casos - Doblaje y desfase gubernamental y Gabinete de seguridad - se trata de remezclas

6
Voz fuera o al margen del campo visual. 
o recombinaciones - collage, para decirlo en términos de Zavala (1999)_ que intentan restarle credibilidad a un discurso - el oficial-y desmantelar las versiones mediáticas sobre ciertos acontecimientos. Al yuxtaponer elementos de procedencia distinta — fragmentos de viejas películas y contenidos mediáticos de actualidad política- se establecen significados con unos recursos a partir de otros. Hay un comentario político implícito, una postura crítica en ese procedimiento. En el primer ejercicio, por comparación, Duarte Ochoa aparece cargado de un turbio significado a partir de un personaje cinematográfico que en escena intenta convencer a quienes lo juzgan de una inocencia impostada, remarcada por las gesticulaciones de un rostro infantilizado - el del actor Peter Lorre-.

Por otro lado, para la cabal comprensión de Gabinete de seguridad en este análisis, se requiere un poco más de información sobre el contexto en el que se publicó. De acuerdo con Simón Vargas Aguilar (2016), la recaptura de Guzmán Loera se realizó “en medio de una complicada situación económica para México, con un dólar que superó la barrera de los 18 pesos [...]; el crudo mexicano en mínimos que no se habían visto en doce años y constantes editoriales de la prensa internacional descalificando al gobierno del presidente Enrique Peña Nieto”.

En ese sentido, la significación del ejercicio opera en dos niveles: 1) la evidente comparación con el doctor Caligari, quien, por efecto de la hipnosis, ha producido en Cesare una personalidad que puede entretener y a la vez resultar letal —Peña Nieto y Guzmán Loera-; 2) la escena de la película recrea un espectáculo de feria y simbólicamente se inserta entre dos sistemas de significación —el gráfico y el sonoro-, con la foto fija de la manifestación y la frase impresa "La sombra de la guerrilla", por un lado, y el discurso en el que se anuncia la triunfante la captura, por el otro. De esta manera, se consigue que las imágenes de la película representen, literalmente, la metáfora popular de la "cortina de humo".
Este tipo de ejercicios, frecuentes en las prácticas creativas del Colectivo Los Ingrávidos, permiten identificar su postura política respecto al uso y apropiación de las imágenes y de los contenidos mediáticos. Pero con estas prácticas, justamente, también puede observarse la forma en la que la participación ciudadana se integra a su vez en los procesos de transmediación.

\section{Conclusiones}

En síntesis, las diferentes manifestaciones del activismo en red se integran a una cultura audiovisual constantemente renovada y vinculada a la cultura digital. Esta renovación es progresiva, en la medida en que se amplían y diversifican los hábitos de creación y producción, de puesta en circulación y participación.

Como señalamos al principio, lo digital y el ciberespacio le dan una naturaleza ubicua a la imagen y eso posibilita el surgimiento de diversas y novedosas formas de producir, crear, difundir o divulgar información, y por lo tanto, nuevos hábitos de socializar, reflexionar y participar a través de lo mediático. Desde sus diferentes trincheras - lo cotidiano o el arte-, los ciudadanos, con sus prácticas creativas, desempeñan un papel fundamental.

Estos procesos muestran las formas por medio de las cuales los usuarios hacen suya la tecnología y los textos mediáticos al incorporarlos de manera creativa al conjunto de sus actividades cotidianas, lo que nos permite constatar procesos de empoderamiento de cierto tipo de productor cultural, aquel que hace valer y pone en práctica, de múltiples maneras, su derecho a la participación en los procesos de ciudadanía.

En este sentido, los productores de la cultura digital, al volverse cazadores de información y contenidos para conectarlos con otros textos y conectarse con otros, se aprecian como uno de los 
principales pilares de la transmediación, porque se apropian de todos los recursos posibles, y no sólo los tecnológicos, para diseminar los contenidos de su interés y transformarlos. De esta forma, podemos hablar de una nueva cultura audiovisual que integra ese conjunto de prácticas que han ido configurando procesos de transmediación y ciudadanía.
Así, la movilidad social y política tiende a estetizarse mediante la intertextualidad y la transmediación, y conforme surgen prácticas de aproximación a contenidos audiovisuales que implican poner en contacto otros contenidos, otros lenguajes y otros formatos, los procesos de participación ciudadana se complejizan en forma progresiva, de lo que resulta un fenómeno a tomar en cuenta para su estudio. $\mathbb{D}$

\section{Bibliografía}

Abril Valdez, José y Gustavo León Duarte, 2017, “Nueva cultura audiovisual y ciberculturas juveniles: sociabilidad y apropiación mediática de jóvenes en el ciberespacio", en Revista Internacional de la Imagen, vol. 3, núm. 2, pp. 1-9.

Ardèvol, Elisenda, Édgar Gómez-Cruz, Antoni Roig y Gemma San Cornelio, 2010, "Prácticas creativas y participación en los nuevos media", en Quaderns del CAC, vol. 13 (1), núm. 34, junio, pp. 27-37.

Appadurai, Arjun, 2001, La modernidad desbordada. Dimensiones culturales de la globalización, Trilce, Montevideo.

Bourriaud, Nicolas, 2014, Postproducción. La cultura como escenario, Adriana Hidalgo Editora, Buenos Aires.

Brea, José Luis, 2007, Cultura_RAM, Gedisa, Barcelona.

Cuevas Portilla, Angélica, 2016, “La escena experimental del cine mexicano: el resurgimiento”, en Florencia Incarbone y Sebastián Wiedemann (coords.), La radicalidad de la imagen. Des-bordando latitudes latinoamericanas, Hambre. Espacio de cine experimental, Buenos Aires, pp. 55-68.

Gravante, Tommaso y Alice Poma, 2013, "Apropiación y emociones: una propuesta teórica desde abajo para analizar las prácticas de Net Activismo", en Francisco Sierra Caballero (coord.), Ciudadanía, tecnología y cultura. Nodos conceptuales para pensar la nueva mediación digital, Gedisa, Barcelona, pp. 257-284.

Gubern, Román, 2014, Historia del cine, Anagrama, Barcelona.

Igarza, Roberto, 2010, "Nuevas formas de consumo cultural: por qué las redes sociales están ganando la batalla de las audiencias", en Comunicación, Media y Consumo, vol. 7, núm. 10, pp. 59-90.

Incarbone, Florencia y Sebastián Wiedemann, 2016, “Prólogo. La radicalidad de la imagen”, en Florencia Incarbone y Sebastián Wiedemann (coords.), La radicalidad de la imagen. Des-bordando latitudes latinoamericanas, Hambre. Espacio de cine experimental, Buenos Aires, pp. 9-14.

Jenkins, Henry, Sam Ford y Joshua Green, 2015, Cultura transmedia. La creación de contenido y valor en una cultura en red, Gedisa, Barcelona. Lipovetsky, Gilles y Jean Serroy, 2009, La pantalla global. Cultura mediática y cine en la era hipermoderna, Anagrama, Barcelona.

Scolari, Carlos, 2013, Narrativas transmedia. Cuando todos los medios cuentan, Deusto, Barcelona.

__ , 2014, "Prólogo", en Carme Ferré Pavia (ed.), El uso de las redes sociales: ciudadanía, política y comunicación, Institut de la Comunicació de la Universitat Autònoma de Barcelona, Barcelona, pp. 10-12.

Vargas Aguilar, Simón, 2016, "La recaptura. El Chapo Guzmán: tercer acto”, en La Jornada, 9 de enero. Disponible en línea: <http://www. jornada.unam.mx/2016/01/09/opinion/008a1pol>.

Zavala, Lauro, 1999, “Elementos para el análisis intertextual”, en Cuadernos de Literatura, vol. 5, núm. 10, pp. $26-52$.

—_ 2007, Manual de análisis narrativo literario, cinematográfico, intertextual, Trillas, México.

\section{Filmografía}

Colectivo Los Ingrávidos, 2015, Doblaje y desfase gubernamental. Disponible en línea: <https://vimeo.com/135520207>.

Colectivo Los Ingrávidos, 2016, Gabinete de seguridad. Disponible en línea: <https://vimeo.com/152362025>.

Lang, Fritz (dir.), 1931, El vampiro de Düsseldorf, Nero-Film A. G., Berlín.

Wiene, Robert (dir.), 1920, El gabinete del doctor Caligari, Decla-Bioscop A. G., Berlín. 